HOME AND COMMUNITY BASED SERVICES AND LIFE SATISFACTION AMONG HOMEBOUND AND POOR OLDER ADULTS

Q. Chen ${ }^{1}$, T. Amano ${ }^{1}$, S. Park ${ }^{2}$, B. Kim³ , 1. George Warren

Brown School of Social Work, Washington University

in St. Louis, 2. Washington University in Saint Louis, 3.

University of New Hampshire

Home and Community Based Services (HCBS) utilization has been proved to be related to higher life satisfaction among older people with homebound or low-income status. However, little evidence exists regarding the role of HCBS utilization on life satisfaction among older people with a combination of homebound and low-income status. This study aims (1) to describe characteristics of older people with homebound and low-income status; (2) to investigate how a combination of homebound and low-income status are associated with their life satisfaction; and (3) to assess the extent to which HCBS utilization moderates the association between the combination of homebound and low-income status and life satisfaction. Data came from 2012 Health and Retirement Study, and the sample included respondents who were 51+ years and who completed a special survey of HCBS utilization $(\mathrm{N}=1,693)$. Result of bivariate analyses showed that socio-demographic characteristics and health status significantly varied across different combination of homebound and low-income groups. Findings from hierarchical linear regression analyses Findings from hierarchical linear regression analyses suggested that the combined status of being homebound and poor was a significant predictor of lower life satisfaction $(\beta=-0.246, \mathrm{p}<.01)$. However, people within this most vulnerable subgroup showed better life satisfaction when they used HCBS $(\beta=0.358, \mathrm{p}<.05)$. These findings suggest that promoting HCBS utilization is an efficient strategy to enhance well-being among those homebound and poor. Further studies are needed to test effectiveness of HCBS with longitudinal data and to investigate details of effective HCBS utilization such as frequency and types of services.

\section{JOB DEMANDS, COPING RESOURCES, AND JOB SATISFACTION AMONG OLDER EMPLOYED MEN IN JAPAN}

K. Harada ${ }^{1}$, H. Sugisawa ${ }^{2}$, Y. Sugihara ${ }^{3}$, S. Yanagisawa ${ }^{4}$, M. Shimmei ${ }^{2}$, 1. Jissen Women's University, 2. J. F. Oberlin University, 3. Tokyo Metropolitan University, 4. Tokushima Universiy

This study examined the additive effects of job demands, job control, and social support and the buffering effects of job control and social support in reducing the negative impact of job demands on job satisfaction among older employed men in Japan. Job demands refer to stressors such as time pressure and workload, whereas job control represents the extent of an employee's decision latitude. We obtained the data from a national probability sample survey of 55-64year men $(n=919)$. In this study, we used only the data from the respondents who were employed $(n=529)$. Hierarchical regression analyses were conducted by controlling for age, education, marital status, employment status, and occupational category. The results indicated that job demands were associated with a lower level of job satisfaction, whereas job control, supervisor support, and co-worker support were associated with a higher level of job satisfaction. Moreover, the job demands $\times$ job control term and the job demands $\times$ co-worker support term were positively significant. Therefore, as for buffering effects, the results suggested that job control and co-worker support were viewed as coping resources, reducing the negative effects of job demands on job satisfaction. Current public policy in Japan is seeking to extend employees' work lives by enabling them to continue their jobs until at least 65 years of age. Since job control and co-worker support seem to play a key role in increasing job satisfaction, organization-level management should be deployed to address job demands in the workplace.

\section{LONGITUDINAL PSYCHOSOCIAL PREDICTORS FOR PERSONAL GROWTH THROUGHOUT ADULTHOOD}

M. Toyama, H. Fuller, J. Hektner, North Dakota State

University

Personal growth is essential in the lives of adults of any age and is associated with a variety of health and well-being outcomes. Building on previous research on psychosocial factors associated with personal growth during adulthood, the present study aims to investigate whether and how psychosocial factors (including work status, generativity, positive relations with others, and spirituality) can influence aging adults' personal growth longitudinally. Using three waves of Midlife in the United States (MIDUS) data from adults with baseline ages of 20 to 75 , two-level hierarchical linear modeling analyses were conducted to examine the effects of psychosocial factors as well as age and gender on levels and trajectories of personal growth over the span of nearly two decades. All the factors predicted levels of personal growth while positive relations and generativity had larger effects relative to the others. In addition, some of the effects were moderated by baseline age or passage of time (i.e., aging). Particularly, the moderated effects involving positive relations were multifaceted. Among those with less positive relations, older people's levels of personal growth remained lower than younger people over time. However, among those with more positive relations, older people reported lower growth initially, but the age difference was no longer confirmed two decades later. In other words, having positive relationships became increasingly important for aging adults to maintain higher personal growth. These findings suggest shifts in life priorities that could influence personal growth among aging adults, and the implications can be informative for future research and practice.

\section{MARITAL QUALITY AND DEPRESSIVE SYMPTOM TRAJECTORIES: A LATENT GROWTH CURVE ANALYSIS OF OLDER COUPLES}

J. Bulanda ${ }^{1}$, T. Yamashita ${ }^{2}$, S. Brown ${ }^{3}$, 1. Miami University, 2. University of Maryland, Baltimore County, 3.

Department of Sociology and Gerontology

Marital quality, and particularly negative marital interaction, is associated with depressive symptomatology, and this relationship appears to be stronger for women than men. However, existing studies generally focus on samples of younger people or newlyweds, use cross-sectional data, examine specific subsamples (e.g., those with chronic illness), and/ or do not utilize dyadic data. We use data from four waves (2006-2012) of the Health and Retirement Study (HRS) to examine trajectories of depressive symptomatology using 